\title{
"Select Crowd Review": A New, Innovative Review Modality for The Thoracic and Cardiovascular Surgeon
}

\author{
Markus K. Heinemann ${ }^{1}$ Roman Gottardi ${ }^{2}$ Peter T. Henning ${ }^{3}$ \\ ${ }^{1}$ Department of Thoracic and Cardiovascular Surgery, \\ Universitätsmedizin Mainz, Mainz, Germany \\ ${ }^{2}$ Cardiac Surgery, MEDICLIN Herzzentrum Lahr, Lahr, Germany \\ ${ }^{3}$ Georg Thieme Verlag KG, Stuttgart, Germany \\ Address for correspondence Markus K. Heinemann, MD, PhD, \\ Department of Thoracic and Cardiovascular Surgery, \\ Universitätsmedizin Mainz, Mainz 55131, Germany \\ (e-mail: mheinema@uni-mainz.de; Peter.Henning@thieme.de).
}

Thorac Cardiovasc Surg 2021;69:387-388.

The quality of scientific articles is traditionally assured by the peer-review process. ${ }^{1,2}$ The Thoracic and Cardiovascular Surgeon (ThCVS) uses double-blind peer review in which both the authors' and the reviewers' identities are kept anonymous. One of the most important issues in today's scientific publishing world is to offer a rapid process without compromising quality or integrity. The whole peer-review workflow, however, is often time consuming until a final decision can be made. ${ }^{1}$ Each year the number of scientific papers submitted continues to grow, in turn increasing pressure on the system. For the individual reviewer, this can result in an overload of requests. Moreover, medicine and natural sciences are subject to expanding specialization, again limiting the number of potential reviewers qualified to evaluate a manuscript in its entirety. This situation is an incentive to explore alternative systems, models, and solutions for quality assurance and sustained efficiency of scientific publications.

\section{Select Crowd Review: An Innovative Form of Collective Peer Review}

The Select Crowd Review process uses mechanisms similar to social media communication. It is an interactive and secure way to accelerate the review process compared with traditional peer review. The Select Crowd Review was first introduced for Thieme's chemical synthesis journal SYNLETT in 2017. It has since been found to allow editors an evaluation of manuscripts within a comparatively short period of time. ${ }^{3,4}$

\section{How It Works}

A selection of several experts, the members of the Crowd, receive a link to the manuscript and can comment on it anonymously via a secure web-interface. The Select Crowd Review meets the requirements of ThCVS's double-blind peer review: only the Crowd Review Editor knows who the reviewers are while monitoring the process. The authors' identities are not revealed to the crowd members, and vice versa.

Each reviewer decides if he or she has time and expertise to comment on the respective article. Participating reviewers see each other's (anonymous) comments and can discuss the research featured in the paper to improve it. They can respond, interact, and enhance it in parallel.

The Crowd Review Editor decides on the termination of the relatively short review period, usually 7 to 10 days. When the review period ends, the manuscript is taken off the platform. In the next step, the Crowd Review Editor evaluates the comments of the reviewers, summarizes them, and makes a first decision (accept/revise/reject). Summary and feedback of the crowd are sent to the authors for consideration and implementation.

\section{What It Offers}

Experience with the Select Crowd Review has shown that the process provides the substantial, high-quality feedback the authors publishing in ThCVS are used to, usually within a few days. This allows editors to come to a decision about a manuscript much faster and therefore helps to shorten the time from submission to an eventual publication.

\section{Submit Your Paper and Try Select Crowd Review Now!}

ThCVS is offering the Select Crowd Review to authors on a voluntary basis:

1. By submitting your manuscript to ThCVS and selecting "Crowd Review" as your preference, you can experience and discover the process for yourself.

2. As in the past, you can also choose exclusively traditional peer review.

We are delighted that Roman Gottardi, MD has accepted our invitation to become the Select Crowd Review Editor. We 
are looking forward with anticipation to see how this new review modality will grow and develop.

The Editors and the Publisher.

\section{References}

1 Schmitz J. https://handbuch.tib.eu/w/index.php?title=Handbuch_ CoScience/Peer_Review\&oldid=3409. Accessed June 26, 2021
2 Johnson R, Watkinson A, Mabe M. 50 1968-2018 Celebrating the 50th Anniversary of STM. 5th edition. International Association of Scientific, Technical and Medical Publishers; 2018. The Hague, The Netherlands

3 List B. Crowd-based peer review can be good and fast. Nature 2017;546(7656):9. Doi: 10.1038/546009a

4 Nguyen TM. The case for crowd peer review. Chem Eng News $2018 ; 96(47)$ 